\title{
Régimen de sanciones administrativas y otros actos administrativos desfavorables en derecho migratorio chileno: parte general
}

\author{
Diego Molina Conzue*
}

\section{RESUMEN}

El presente artículo busca analizar en qué casos, y bajo qué justificación, es posible aplicar la distinción entre actos administrativos desfavorables y sanciones administrativas. Lo anterior supone estudiar los elementos que permiten catalogar un acto administrativo como sanción administrativa, así como las normas y derechos existentes en materia migratoria relativos al ingreso de los migrantes al territorio de un Estado y a las situaciones posteriores a dicho ingreso.

Migración; sanción administrativa; acto administrativo desfavorable

\section{Regime of administrative sanctions and other unfavorable administrative acts in chilean migratory law: general part}

\begin{abstract}
This article study in which cases, and under what reasons, it is possible to apply the distinction between unfavourable administrative acts and administrative sanctions. That requires analyse the elements which allow us to make a distinction between an administrative act as an administrative sanction, as well as migratory rules and rights related to entry of migrants into the territory of a State and subsequent situations to that entry.
\end{abstract}

Migration; administrative sanction; unfavorable administrative act

* Licenciado en Ciencias Jurídicas, Pontificia Universidad Católica de Valparaíso, Chile. Profesor de la Facultad de Derecho, Pontificia Universidad Católica de Valparaíso, Chile. ORCID: http://orcid.org/00000002-8312-4863.Correo electrónico: diego.molina@pucv.cl

Artículo recibido el 27.5.20 y aceptado para su publicación el 20.12.20. 


\section{INTRODUCCIÓN}

C hile ha experimentado, en la última década, un gran aumento de su población de extranjeros. Así, se estimó, que a fines de 2018 la población inmigrante en Chile asciende a 1.492 .522 personas $^{1}$, en circunstancias que, en el 2009, dicha cifra apenas alcanzaba las 208.722 personas $^{2}$. Dicha realidad, unida a la existencia de una legislación arcaica y concebida bajo el esquema de la seguridad nacional, llevó a un constante examen de la Ley de Extranjería vigente, Decreto Ley $N^{\circ} 1.094$, de 1975, del Ministerio del Interior (en adelante LE) ${ }^{3}$. Del mismo modo, ha llevado a agilizar y aprobar el trámite legislativo del proyecto de Ley de Migración y Extranjería, Boletín 8.970-06 (en adelante PLM), en miras a dotar a nuestro país de una nueva normativa migratoria ${ }^{4}$.

Especialmente atendidos los efectos negativos que generan ciertas actuaciones de la Administración, se hace del todo necesario analizar la naturaleza jurídica, sentido y alcance de aquellos preceptos que habiliten a la autoridad a disponer estas medidas. Ahora bien, el estudio de los actos desfavorables existentes en materia migratoria, si bien tiene importantes implicancias constitucionales e internacionales, atendida la existencia de un conjunto de derechos que esas normativas reconocen a los extranjeros, también debe considerar las categorías y criterios propios del derecho administrativo, atendida no solo la naturaleza de la función realizada, sino que también el órgano competente en la materia.

En el presente escrito deseamos reflexionar acerca de la naturaleza jurídica de los actos desfavorables en materia migratoria, prescritas tanto por la LE como por el PLM, distinguiendo entre aquellos que no constituyen sanciones administrativas, de aquellos no son manifestaciones del ejercicio de la potestad sancionatoria de la Administración del Estado. Una importante consecuencia de lo anterior será determinar en qué casos se deben aplicar los principios propios del derecho administrativo sancionador, así como qué principios o garantías son aplicables a los actos no sancionatorios. A lo dicho sumamos el hecho de que, si bien la presente distinción es realizada por la doctrina administrativista nacional y extranjera, los textos nacionales relativos al derecho migratorio han agrupado bajo la categoría de sanciones administrativas todos aquellos actos impuestos frente a cualquier hecho que conforme con la normativa migratoria vigente se deba aplicar ${ }^{5}$.

Por lo anterior es que, en primer lugar, se abordará la distinción entre la figura de sanción administrativa y otros actos administrativos de contenido desfavorable. En segundo lugar, se pretende aplicar dichas categorías en materia migratoria, distinguiendo

\footnotetext{
${ }^{1}$ Instituto Nacional de Estadísticas y Departamento de Extranjería y migración, 2020, p.19.

${ }^{2}$ Fuentes y Hernando, 2019, p. 383.

${ }^{3}$ Véase Aninat y Sierra, 2019, p. 35. En el mismo sentido, véase Stang, 2016, pp. 83-107.

${ }^{4}$ A la fecha de remisión del presente artículo, el PLM había sido remitido al Tribunal Constitucional para un control preventivo de constitucionalidad, previo requerimiento de un cuarto de los diputados en ejercicio (causa Rol N 9.930-2020).

${ }^{5}$ Dellacasa y Hurtado, 2015, pp. 143-144.
} 
dos grandes grupos normativos, y cuya inobservancia permite identificar la naturaleza jurídica de los actos administrativos que se dicten.

\section{SANCIÓN ADMINISTRATIVA Y OTROS ACTOS DESFAVORABLES}

Nieto nos señala que "[...] en el ordenamiento jurídico están previstas diversas consecuencias jurídicas muy parecidas, e incluso idénticas, a las sanciones administrativas y es el caso que importa distinguirlas con absoluta precisión habida cuenta de que el régimen jurídico de las sanciones es exclusivo de ellas"6.

La distinción anterior es del todo necesaria, ya que el ejercicio de la potestad sancionatoria del Estado requiere el cumplimiento de ciertas exigencias. Así, la conceptualización de la sanción administrativa entendida como un especial acto administrativo revestirá la mayor de las importancias.

Sobre el particular, la doctrina ha diferenciado entre una noción amplia y una noción restringida de sanción administrativa. Bermúdez señala que, "Desde una perspectiva amplia, se estimará como sanción toda aquella retribución negativa dispuesta por el ordenamiento jurídico como consecuencia de la realización de una conducta. [...] Por consiguiente, en este sentido, será sanción administrativa todo gravamen o decisión desfavorable impuesta por la Administración a un administrado"7.

Por su parte, desde una perspectiva estricta, serán sanciones administrativas aquellas retribuciones negativas previstas como tales por el ordenamiento jurídico como consecuencia de una infracción administrativa ${ }^{8}$.

En el régimen español, tanto la doctrina como la jurisprudencia han señalado que ciertos actos, no obstante tener un contenido desfavorable, no constituyen una sanción administrativa, pues, o bien no son consecuencia de una conducta ilícita ( $v$.gr. la expropiación o caducidad) o, siendo consecuencia de un acto ilícito, carecen de una finalidad represiva o reaccional, como lo son las medidas de restablecimiento de la legalidad ${ }^{9}, \mathrm{y}$ las medidas de reparación o resarcimiento ${ }^{10}$.

En la misma línea, la doctrina nacional, al diferenciar entreactos desfavorables en general y sanciones administrativas, señala que: “[...] a) la sanción administrativa es

${ }^{6}$ Nieto, 2016, p. 156. En el mismo sentido, Osorio señala que “[...] existen diversas situaciones que se dan en la práctica, en las cuales, por motivos múltiples, los órganos de la Administración del Estado causan determinados perjuicios o menoscabo económico a los particulares, los cuales no configuran sanciones administrativas en stricto sensu"; OsORIO, 2017, p. 39.

${ }^{7}$ Bermúdez, 1998, p. 323.

${ }^{8}$ Bermúdez, 1998, p. 326.

${ }^{9}$ Medidas que "[...] no van más allá de esa restauración de la legalidad vulnerada, es decir, dejan al particular en la situación inicial, a diferencia de lo que ocurre, por ejemplo, cuando se le impone una multa. A veces se estudia este problema bajo la rúbrica de la distinción entre sanciones administrativas y policía”; Huergo, 2007, p. 249.

${ }^{10}$ Cordero, 2013, p. 85. Es más, el mencionado autor, al definir a las sanciones administrativas señala que ellas tienen una finalidad esencialmente represora; Cordero, $2014 \mathrm{a}$, p. 401. 
consecuencia de una conducta ilícita o infracción; y b) la sanción administrativa tiene una finalidad esencialmente represiva o de castigo. De esta forma, la sanción administrativa es un acto desfavorable que afecta la esfera jurídica de un particular con una finalidad represora frente a una infracción o conducta ilícita"11.

Respecto del primer criterio de distinción, y como elemento esencial para el ejercicio de potestades sancionatorias, es menester encontrarse frente a una infracción administrativa, esto es, ante " $[\ldots .$.$] el incumplimiento de un deber, obligación o prohibición del$ ordenamiento jurídico administrativo" 12 al que se encuentra sujeto un individuo. El ordenamiento jurídico, con el objetivo de procurar la satisfacción de ciertas finalidades consideradas como valiosas, sujeta el comportamiento de los particulares a un conjunto de parámetros, cuya inobservancia habilitará a la autoridad administrativa a adoptar las medidas necesarias para obtener el cumplimiento de las finalidades que justifican el establecimiento de deberes, obligaciones y prohibiciones. Sin embargo, no todo compartimento calificable como contrario a derecho puede ser catalogado como una infracción administrativa, toda vez que dicha contravención debe suponer el incumplimiento de un imperativo jurídico al cual el particular se encuentra sometido.

Asimismo, y como consecuencia de lo anterior, toda vez que por medio de las sanciones administrativas se aplica una consecuencia perjudicial para un particular fundada en el incumplimiento de prohibiciones, deberes y obligaciones a los que se encontraba sujeto, y cuya inobservancia ha sido prevista como infracción, dichas consecuencias perniciosas pretenderán retribuir el desvalor de la conducta realizada.

En todo caso, es importante tener presente que "La sanción es [...] una de las tantas herramientas que tiene la autoridad para cumplir sus fines y lograr la satisfacción del interés general" 13 . En efecto, y con el fin de procurar que la medida adoptada logre de la forma más óptima posible la satisfacción de tales fines e interés, "La autoridad puede considerar que es más adecuado para el cumplimiento de la finalidad respectiva la adopción de otras medidas o simplemente un mero llamado [de] advertencia al infractor para que corrija su comportamiento"14. Así, y si bien, al igual que las sanciones administrativas, los otros actos desfavorables tienen por pretensión satisfacer ciertos intereses públicos ${ }^{15}$, la decisión de su aplicación es realizada, incluso, con independencia del perjuicio que puede causar para el particular, el que no estará en primer plano y cuya presencia será irrelevante para la justificación de la medida ${ }^{16}$.

\footnotetext{
${ }^{11}$ Cordero, 2013, p. 84. Véase a Osorio, 2017, pp. 30-31.

12 Osorio, 2017, p. 30.

13 Gómez, 2020, p. 207.

${ }^{14}$ Gómez, 2020, pp. 206-207.

${ }^{15}$ ENTEICHE señala que la sanción administrativa " [...] tiene como objetivo la represión de una conducta que infringe el ordenamiento jurídico, a fin de resguardar un bien jurídico que el organismo sancionador debe cautelar. Por esto si un acto de castigo [, o mejor dicho lesión,] tiene por objeto otro propósito, no será una sanción sino algo diverso"; ENTEICHE, 2014, p. 14.

${ }^{16}$ Huergo, 2007, p. 225. En un sentido similar, véase a Letelier 2018, pp. 921-923.
} 
Conforme con lo dicho previamente, y en la sede que nos convoca, es posible afirmar que si bien todo acto desfavorable pretende la satisfacción de una determinada finalidad o interés público, en el caso de las sanciones administrativas, y en miras a procurar tal objetivo, el ordenamiento jurídico ha decidido configurar un conjunto de prohibiciones, deberes y obligaciones, cuya inobservancia ha tipificado como infracciones, asociándoles ciertas consecuencias perniciosas. Por su parte, en caso de que se impongan imperativos jurídicos, pero estas no se tipifiquen, y siguiendo el planteamiento de Nieto, dichos comportamientos serían susceptibles de ser consideramos como infracciones, habida cuenta que " $[\ldots .$.$] no es imaginable que la ley se moleste en imponer mandatos y prohibi-$ ciones para luego no dar relevancia alguna a su incumplimiento" ${ }^{17}$. En otros hechos, en cambio, en caso de la comisión de ciertas infracciones, regula otras medidas de contenido desfavorable con las que se pretende alcanzar el cumplimiento de finalidades específicas.

Finalmente, aún es posible encontrar otros casos en que ha dispuesto que se adopten ciertas medidas administrativas desfavorables, pese a que no nos encontremos ante comportamientos susceptibles de ser calificados como infracciones, toda vez que el particular no se encontraba sujeto a algún imperativo jurídico al momento de la realización de hechos jurídicamente relevantes (como es el caso de la expulsión administrativa fundada en el hecho de haber ingresado existiendo causales de prohibición de ingreso).

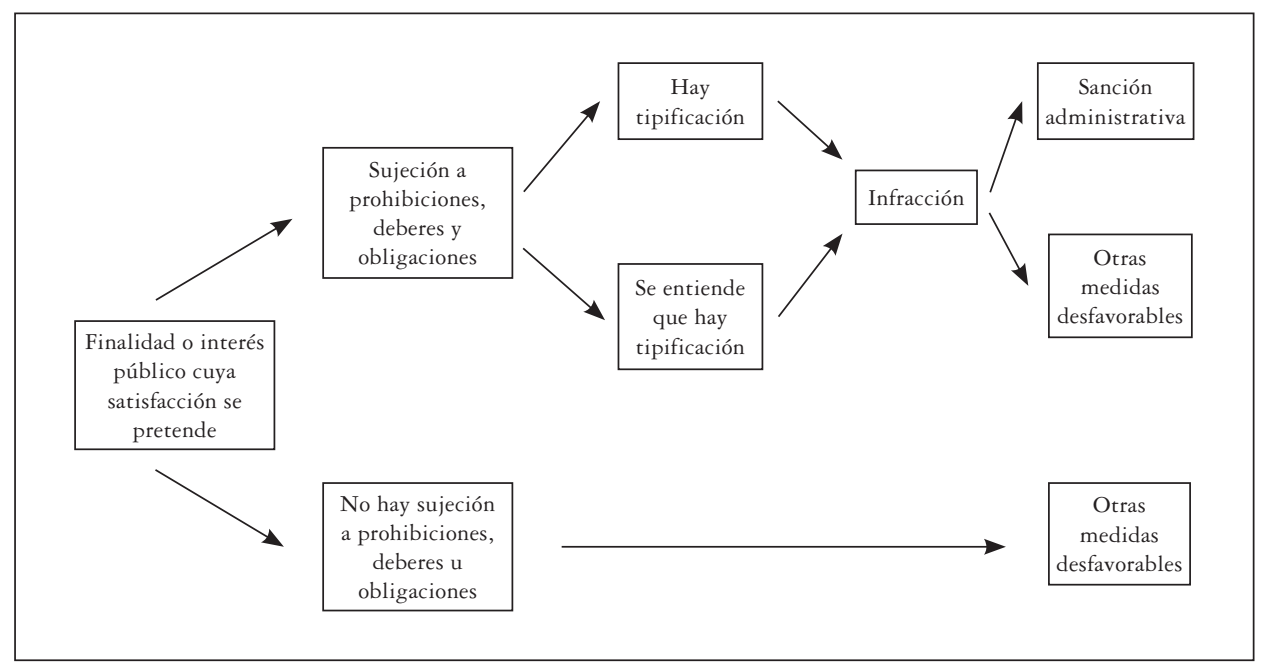

Cuadro resumen $\mathrm{N}^{\mathrm{o}} 1$

${ }^{17}$ Nieto, 2016, p. 359. 
A lo dicho previamente, es menester aclarar que, en la aplicación de una sanción ante la comisión de la infracción administrativa, también nos encontramos frente a una finalidad preventiva. "Esa es una de las razones por las que no se exige, para el cumplimiento del tipo, que la conducta produzca daño o consecuencia gravosa alguna" 18 .

Por último, identificar en qué casos la Administración del Estado ejercerá potestades sancionatorias revestirá de la mayor importancia a efecto de aplicar los principios y régimen de garantías propio del derecho administrativo sancionador. En efecto, " [...] el Derecho Administrativo Sancionador [sic] debe ser entendido como un régimen de garantías que limite el poder de castigo de la Administración"19.

Como punto de partida de la temática, es importante recordar que nuestro Tribunal Constitucional desde la sentencia recaída en causa rol 244, ha dicho que al derecho administrativo sancionador le son aplicables los principios constitucionales del orden penal matizados, pues tanto dicha disciplina como el derecho penal provienen de un único ius puniendi estatal ${ }^{20}$.

De ello, “[...] en el plano constitucional, los principios que rigen la potestad sancionadora de la Administración no solo constituyen el fundamento de validez de las normas infraconstitucionales que la rigen, sino que también son elementos de interpretación de las mismas y pueden ser aplicables de forma directa, en la medida que gocen de la densidad prescriptiva suficiente" 21 , actuando como "[...] una herramienta de integración de aquellos vacíos o lagunas legales no previstas por el legislador y permit[iendo] sistematizar, desde una perspectiva dogmática, el análisis y estudio" 22 .

Es más, "[...] de prevalecer la noción amplia de sanción administrativa, si la entendemos como cualquier mal recibido $-\mathrm{y}$ aplicando a ella todos los principios del ius puniendi [...]-, la administración [sic] del Estado vería severamente limitada su capacidad discrecional para tomar decisiones en cualquier materia que signifique limitar o recordar prestaciones, pagos o cualquier tipo de beneficio, establecido previamente a favor de los particulares. [...] Asimismo, se confundiría la relación género y especie que hay entre los actos administrativos desfavorables y la sanción administrativa decretada

${ }^{18}$ Bermúdez, 1998, p. 327. Nieto, por su parte, da cuenta que "[...] el intervencionismo púbico es consecuencia de una ideología determinada: el Estado asume la garantía de la intangibilidad de determinados bienes sociales y colectivos -a los cuales da rango jurídico-, que pretende salvaguardar con medidas de prevención que cristalizan en la conminación e imposición de castigos a los infractores”; Nieto, 2016, p. 148.

19 Cordero Vega, 2020, p. 241.

20 "Que los principios inspiradores del orden penal contemplado en la Constitución Política de la República han de aplicarse, por regla general, al derecho administrativo sancionador, puesto que ambos son manifestaciones del ius puniendi propio del Estado"; Tribunal Constitucional, 28.8.1996, rol 244-2016, cons. $9^{\circ}$. "Dicha aplicación matizada, o más bien, la reinterpretación propia de los principios del orden administrativo sancionador viene dada, en definitiva, porque las sanciones administrativas carecen del mismo reproche ético y social que tienen las sanciones penales”; BERMúdEz, 2014, pp. 335-336.

${ }^{21}$ Cordero, 2014a, p. 407.

22 Cordero, 2014a, p. 408. 
o dictada por un acto administrativo y la finalidad de la sanción administrativa en las políticas públicas dictadas" 23 .

En todo caso, si analizamos la jurisprudencia constitucional, es posible apreciar que, para efecto de aplicar las garantías procedimentales relativas al ejercicio de la potestad sancionatoria de la Administración del Estado, se ha utilizado un concepto amplio de sanción administrativa. Por su parte, tratándose de las garantías sustantivas, el Tribunal Constitucional ha optado por emplear un concepto restringido de sanción administrativa $^{24}$.

La Contraloría General de la República, en cambio, emplea un concepto amplio de sanción administrativa, especialmente para dar ciertos resguardos a los particulares frente a actos administrativos con efectos desfavorables. De hecho, emplea un concepto sustancial de sanción, la que se encuentra centrada en su significación ético-social reducida frente a las penas ${ }^{25}$.

Conforme con lo dicho, tratándose de los actos administrativos desfavorables no sancionatorios, no serían aplicables aquellos principios sustantivos propios de las sanciones administrativas, quedando aquella actividad únicamente restringida, prima face, por los límites comunes del derecho administrativo.

Pese a lo anterior, y como desarrollaremos en el siguiente apartado, ello no quiere decir que, al menos en materia migratoria, el análisis quede restringido a las categorías del derecho administrativo común, toda vez que, por la naturaleza de la materia regula$\mathrm{da}$-que incluso puede llevar a decidir acerca de la permanencia o no de una persona en territorio nacional-, como por la regulación internacional y constitucional correspondiente, la autoridad administrativa se encontrará restringida en su actuar, garantizándose así ciertos resguardos al particular.

\section{RÉGIMEN MIGRATORIO Y ACTOS DESFAVORABLES}

\section{Control migratorio de ingreso}

Como punto de partida para referirnos a la regulación de las facultades migratorias del Estado, debemos tener en cuenta que los instrumentos internacionales ${ }^{26}$ reconocen el derecho a poder salir del territorio de un Estado y poder residir y moverse dentro de él, en la medida que se cumpla con su legislación interna. En otras palabras, se reconoce el derecho a emigrar (salir del territorio de un Estado) y a residir y desplazarse en su interior, siempre que se cumpla con la legislación estatal. En cambio, existe silencio en

23 OsOrio, 2017, p. 28.

${ }^{24}$ Cordero, 2013, pp. 86-88.

25 Cordero, 2013, p. 90.

26 Véase el Pacto Internacional de Derechos Civiles y Políticos, artículo 12; Convención Americana de Derechos Humanos, artículo 22; y Convención Internacional sobre la Protección de los Trabajadores Migratorios y sus Familiares, artículos 8 y 39. 
lo que a derecho a inmigrar se refiere, esto es, el derecho a poder ingresar al territorio de un Estado ${ }^{27}$.

Ahora bien, pese a constatar la inexistencia del reconocimiento internacional de tal derecho, ello no significa que los Estados sean totalmente autónomos para determinar el ingreso de personas ${ }^{28}$, ya que, al fijar sus políticas migratorias respecto de personas que no son sus nacionales, debe actuar de forma compatible con los derechos humanos. De este modo, si bien el Estado cuenta con discrecionalidad para determinar sus políticas migratorias, los objetivos que estas persigan deben respetar los derechos de las personas migrantes ${ }^{29}$. En otras palabras “[...] el reconocimiento y garantía de los derechos mínimos de los inmigrantes no implica la negación de las facultades soberanas de control migratorio" 30 , cuyo ejercicio, con todo, encontrará diversas restricciones ${ }^{31}$, dentro de estas una de las de mayor importancia es el derecho a la no discriminación ${ }^{32}$. Las normas de ingreso son una invitación condicionada para entrar al territorio del Estado.

De ello, y bajo el escrutinio de la normativa internacional, la Magistratura Constitucional acierta en afirmar que "[...] los extranjeros tienen el derecho de emigrar, pero no importa ello un deber correlativo de los Estados de aceptar la inmigración, salvo excepciones como el refugio político y el asilo" 33 , debido a que aquello es una manifestación de la soberanía estatal ${ }^{34}$.

${ }^{27}$ En el sistema interamericano de protección de los derechos humanos, "[...] conforme a la Convención, solo los nacionales tienen el derecho a entrar a su propio país. Este derecho es entonces el que se encuentra más estrictamente ligado a a la preservación de la soberanía de los Estados, pues implica que si bien toda persona tiene derecho a salir de cualquier país, únicamente los naciones tienen derecho a entrar al país del cual son nacionales"; Uprimny y SÁnchez, 2019, p. 649. En el mismo sentido, Arlettaz, 2014, p. 23.

28 DíAz, 2016, p. 183.

${ }^{29}$ Corte Interamericana de Derechos Humanos, 23.11.2010, caso Vélez Loor vs Panamá, párr. 97.

${ }^{30}$ Domínguez, 2016, p. 193.

31 El Comité de Derechos Humanos en su Observación General N² 27, de 1999, nos señala que "las restricciones permisibles deben ser compatibles con otros derechos consagrados en el pacto, y, en particular, con los principios fundamentales de igualdad y no discriminación. Por tanto, no pueden hacerse distinciones por raza, color, sexo, idioma, religión, opinión política o de otra índole, origen nacional o social, posición económica, nacimiento o cualquier otra condición social". Para el sistema interamericano véase a UPRIMNY y SÁNCHEZ, 2019, pp. 651-653.

${ }^{32}$ Lo dicho supra se debe a la gran discrecionalidad con que cuentan los Estados respecto de su política migratoria general, que puede llevar a emplear el factor nacionalidad, como categoría sospechosa, al no dar suficiente fundamentación respecto de un trato especial para los extranjeros, especialmente en lo tocante a acceso a derechos. De ello, los Estados "tienen la obligación de garantizar el principio de la igualdad ante la ley y no discriminación independientemente del estatus migratorio de una persona en un Estado"; Corte Interamericana de Derechos Humanos, 28.08.2014, caso Personas Dominicanas y Haitianas Expulsadas vs República Dominicana, párr. 398. Es más, en nuestro país el Tribunal Constitucional ha señalado que, "[...] distinguir los derechos de los extranjeros respecto de los chilenos requiere habilitaciones expresas en la Constitución. Estos criterios distintivos no pueden exceder el marco normativo constitucional, legal e internacional que califica de diferencia odiosa y sospechosa el uso de la categoría extranjero/nacional"; Tribunal Constitucional, 04.07.2013, rol 2.273-2012, cons. $33^{\circ}$.

33 Tribunal Constitucional, 04.07.2013, rol 2.273-2012, cons. $41^{\circ}$.

${ }^{34}$ Acerca de la diferenciación entre los derechos de los extranjeros y los nacionales, véase ARLETTAZ, 2014, pp. 35-52. 
En nuestro régimen constitucional, el artículo $19 \mathrm{~N}^{\circ} 7$, letra a) recoge la libertad ambulatoria, en cuya conformidad todas las personas, inclusive los extranjeros, podrán ingresar a territorio nacional, permanecer en cualquier lugar de la República, trasladarse de un lugar a otro en su interior, así como salir de su territorio, a condición de que en todos esos casos se guarden las normas establecidas en la ley y salvo siempre el perjuicio de terceros ${ }^{35}$.

De esta manera, si bien la Constitución ha reconocido el derecho a inmigrar, elevando los estándares internacionales fijados en la materia ${ }^{36}$, reconoce que el ejercicio del mismo deberá desarrollarse en conformidad con la regulación dada por la ley. Por ello, el problema de la definición e implementación de controles migratorios se encuentran en las modalidades y condiciones de ejercicio de la libertad ambulatoria establecidas por la ley ${ }^{37}$.

Tener presente lo anterior es de suma importancia para todo análisis que se realice en materia migratoria, pues "La libertad ambulatoria o de desplazamiento es un derecho fundamental y, como tal, el Estado debe adecuar su comportamiento al mismo, tanto en cuanto constituye un límite a su actuar, como un criterio rector para su actuación" 38 .

Como segunda idea, al tratar el fenómeno migratorio nos referimos al comportamiento de personas extranjeras, esto es, personas que no son nacionales del Estado de acogida, motivo por el que a su respecto no existe un vínculo permanente generador de derecho y deberes.

De este modo, los extranjeros solo se encontrarán vinculados con el Estado de acogida en la medida que hayan ingresado a su territorio. En efecto, "[...] cada Estado solo puede dictar leyes y hacerlas cumplir dentro de las fronteras de su propio territorio; ninguno puede pretender que sus normas jurídicas sean respetadas más allá de los confines territoriales" 39 . Abogar por la obligatoriedad jurídica de las leyes migratorias

${ }^{35}$ Respecto de esta norma, el Tribunal Constitucional, conociendo de una inaplicabilidad deducida en contra de una causal de prohibición de ingreso al país, estimó que: “[...] la Constitución en materia de titularidad específica del derecho fundamental de libertad de locomoción, no realiza ninguna distinción que valide un tratamiento diverso entre extranjero y nacional. [...] Lo anterior implica que el derecho de emigrar que tiene todo extranjero se correlaciona con su derecho de inmigración en Chile, cuyo ejercicio, pero no el derecho mismo, puede ser modulado, regulado y limitado 'a condición de que se guarden las normas establecidas en la ley y salvo siempre el perjuicio de terceros””. Tribunal Constitucional, 04.07.13, rol 2.273-2012, cons. $35^{\circ}$.

${ }^{36}$ En efecto, diversos cuerpos normativos internaciones, como el Pacto Internacional de Derechos Civiles y Políticos, la Convención Americana de Derechos Humanos y la Convención Internacional sobre la Protección de los Trabajadores Migratorios y sus Familiares, condicionan el derecho a desplazarse dentro del territorio del Estado y residir en su territorio al ingreso legal, consagrando como derecho la facultad de salir del territorio de un Estado, mas guardan silencio respecto del derecho a ingresar al territorio de un Estado del que no se es nacional. En otras palabras, "En las normas internacionales no existe reconocimiento expreso de un derecho a inmigrar, solo de los derechos de emigrar, circular libremente una vez se ha ingresado y el de retornar al Estado del que se es nacional”, DíAz, 2016, p. 207.

\footnotetext{
37 Véase a Aldunate, 2008, p. 248.

38 Molina, 2019, p. 238.

39 Alessandri et al., 2005, p. 269.
} 
respecto de los extranjeros que se encuentran fuera de las fronteras del Estado que les dicta supondría afirmar que dicho Estado puede dictar normas que generen efectos extraterritoriales.

Acerca del particular, y como ha dicho Pérez Serrano a propósito de la relación existente entre nacionales y extranjeros:

“[...] los primeros están sujetos al imperium estatal por razón de su misma condición de nacionales, por el vínculo que los une con la comunidad espiritual (Nación) ${ }^{40}$ y por la política (Estado), lazo que supone intimidad de conexión, título de cooperaciones y motivo de obediencia, y que no desaparece por la ausencia del territorio. En cambio, los extranjeros solo a través de este, y mientras dure su estancia allí, están sometidos al Estado (cuestión independiente es la de sus bienes)" ${ }^{41}$.

De lo anterior, por esta razón, las normas legales migratorias no tienen un efecto vinculante para el extranjero que se encuentre fuera del territorio del Estado al que desea ingresar. Por cierto, ello en caso alguno supone que el migrante no deberá adecuar su comportamiento a las disposiciones que correspondan en caso de pretender ingresar regularmente al territorio del Estado de destino.

Los requisitos de ingreso no tienen el valor de obligaciones, sino que condiciones de acceso. Así, el extranjero que ingresa a territorio nacional no infringe obligaciones, pues no se encuentra sometido a estas, sino que inobserva las condiciones dispuestas para acceder de forma regular a un espacio físico determinado.

Por lo anterior, el extranjero que ingresa sin cumplir con las condiciones de acceso es una persona que nunca debió haber ingresado a suelo nacional, quedando en un estado permanente de irregularidad, salvo que se regularice mientras se encuentra en el Estado, o bien, habiendo salido de su territorio, ingrese nuevamente cumpliendo las exigencias legales ${ }^{42}$.

A este respecto, también es conveniente recordar que:

"El criterio de cruce de frontera o de entrada en el territorio es importante para distinguir la no admisión de la expulsión en sentido amplio, ya que, según el Relator Especial, el extranjero que ha flanqueado las barreras de control de las autoridades de inmigración y que se encuentra en el territorio del Estado de 'acogida', fuera

${ }^{40}$ Es menester señalar que el concepto de nación no es equivalente al de nacionalidad, tanto en cuanto el primero alude al "[...] conjunto de personas de un mismo origen étnico y que generalmente habla un mismo idioma y tienen una tradición común” (SILVA, 1997, p. 181); mientras que el segundo alude a aquellas personas que gozan de un vínculo jurídico con el Estado.

41 Pérez, 1994, p. 115. En la misma línea, García Maynez señala que, "Desde el punto de vista del derecho público, el territorio es simplemente la base real del ejercicio del imperium"; García, 1965, p. 99.

42 Véase Cox, 2008, pp. 357 y siguientes. 
de las zonas especiales de detención de los aspirantes a la admisión, solo puede ser objeto de expulsión y ya no de no admisión" ${ }^{43}$.

En virtud de tal análisis, al no poder afirmarse que los extranjeros están sujetos a obligaciones, no es procedente entender que los actos con efectos desfavorables que se adopten teniendo como elemento fáctico el ingreso irregular del extranjero, esto es, el hecho de no cumplir las condiciones fijadas por las normas relativas al control de ingreso, tendrían una finalidad sancionatoria, toda vez que los mismos no persiguen retribuir el comportamiento infractor de un particular. Su interés es velar y lograr un ingreso ordenado al país ${ }^{44}$. Es más, incluso es posible afirmar que, en caso de disponerse una expulsión por tal vía, la misma tendría la finalidad de restablecer el imperio del derecho.

De todas formas, y como ya se adelantó, afirmar que el estatuto de garantías propio de las sanciones administrativas no es aplicable a un acto administrativo desfavorable, en ningún caso supone dejar al particular afectado carente de garantías, especialmente en sede migratoria, habida cuenta de la regulación constitucional e internacional correspondiente.

Si bien en el caso de las garantías procedimentales, y como ha señalado el Tribunal Constitucional, son aplicables las garantías propias del régimen sancionador, no ocurre lo mismo tratándose de las garantías sustantivas.

En torno a las primeras, es posible tan solo mencionar que ellas tiene por finalidad asegurar el derecho a un debido procedimiento administrativo, permitiéndosele al particular, en consecuencia, formular alegaciones y aportar antecedentes que juzgue necesario para su defensa. Del mismo modo, se encontrará asistido por el derecho a obtener una decisión fundada y sujeta a revisión judicial ${ }^{45}$.

Respeto de las segundas, y conforme con lo observado en la actual normativa de extranjería, los actos desfavorables no sancionatorios tendrían por objetivo último la salida de una persona del territorio nacional (expulsión por ingresar sin cumplir los requisitos exigidos por la ley -artículo 17 de la actual LE, en relación con su artículo 15 , y artículo 68 y 69- y orden de abandono, y eventualmente expulsar, como consecuencia de los rechazos y revocaciones respecto de personas que ingresan al país pese a existir a su respecto alguna prohibición de ingreso o haber ingresado con documentos falsificados, adulterados o expedidos a favor de otras personas -artículo 67 de la actual LE, en relación con los artículos $63 \mathrm{Ns}^{\circ} 1$ y 3 y $65 \mathrm{~N}^{\circ} 1-$. Lo dicho precedentemente se mantiene en el PLM, ya que conforme con los artículos $127 \mathrm{~N}^{\circ} 1$ y $128 \mathrm{~N}^{\circ} 1$, se contempla como causal de expulsión el ingreso al país a pesar de la existencia de una prohibición de ingreso. Asimismo, el PLM mantiene que se dispondrá la orden de abandono, y eventual expulsión, en caso de rechazo de solicitudes o revocación de permisos de personas respecto de las cuales existe prohibición de ingreso (artículos 91, $88 \mathrm{~N}^{\circ} 2$, $89 \mathrm{~N}^{\circ} 1,90 \mathrm{~N}^{\circ} 1,91$ y $\left.127 \mathrm{~N}^{\circ} 3\right)$.

\footnotetext{
43 Камто, 2006, p. 57.

${ }^{44}$ Letelier 2018, pp. 922-923.

45 Véase a Cordero, 2014b, pp. 189-215.
} 
Por ello, aquellos cuerpos normativos que les consagren, conforme con el artículo $19 \mathrm{~N}^{\circ} 26$ de la Constitución, deben ser normas de rango legal en sentido estricto. Lo anterior impide la colaboración de la potestad reglamentaria en su establecimiento. "Se trata de una competencia constitucional exclusiva del legislador, que delimita tanto su propio ámbito competencial como el de otros órganos del Estado, especialmente el que corresponde a la potestad reglamentaria" ${ }^{46}$. Del mismo modo, dichas medidas deberán ser idóneas a los fines perseguidos, necesarias y proporcionales en sentido estricto. Por último, y si bien en principio el Estado pareciere ser soberano para determinar las condiciones de ingreso, "[...] el espacio de discrecionalidad de los Estados para definir sus políticas y normas migratorias está también determinado por la relación de interdependencia entre el derecho interno y el derecho internacional, en la que emerge el principio de respeto universal y la observancia de los derechos humanos y de las libertades fundamentales, cuyos titulares son también, por vía del principio de igualdad y no discriminación, las personas migrantes" 47 .

A la fecha, la amplia discrecionalidad administrativa presente en nuestra normativa “[...] constituye uno de los espacios en que es más factible vulnerar el adecuado trato que, en base al principio de igualdad, [...] se exige a los extranjeros migrantes, especialmente en lo que dice relación con las discriminaciones de jure y de facto" ${ }^{4}$.

En cuanto a los supuestos de hecho con ocasión de que dichas medidas se apliquen, y pese a la necesidad de encontrarse debidamente establecidos en la ley, no es necesario que se desarrolle o describa una conducta infraccional específica. En efecto, el foco se encuentra en la descripción de los requisitos de ingreso, especialmente respecto de las prohibiciones de acceso, las que deben ser lo más completa y descriptivas posibles, en la medida que fijan las condiciones con las que se puede ingresar válidamente al territorio de la República ${ }^{49}$. Además, y a efecto de emitir una decisión debidamente fundada, la

\footnotetext{
46 Bassa y Torres, 2020, p. 1038.

${ }^{47}$ LAGES, 2019, p. 37.
}

48 Molina, 2018, p. 6. Respecto del régimen de visados, autores como Bassa y Torres sostienen que la cláusula general de discrecionalidad presente en el artículo 13 de la LE, para el otorgamiento de las visaciones, de sus prórrogas y la concesión o no de la permanencia definitiva será ejercida discrecionalmente por el Ministerio del Interior, atendiendo especialmente a la conveniencia o utilidad que reporte al país su concesión y a la reciprocidad internacional, confiere el desarrollo de los conceptos jurídicos que constituyen los criterios justificadores de actuación administrativa quedan a merced de los criterios hermenéuticos que la Administración aplique al caso concreto, pudiendo vulnerar la igualdad ante la ley; BASSA y Torres, 2015 , p. 115. En la misma línea, DíAz señala que las amplias facultades discrecionales que se confieren a la Administración en tema de visados se traducen en que las decisiones administrativas no serán construidas a partir de criterios de razonabilidad establecidos por una norma legal; DíAz, 2016, p. 202.

49 " $[\ldots .$.$] solo mediante la ley se puede regular este derecho. Impera en la materia el principio de reserva$ legal con cualidad absoluta. Jamás por decreto u otra normativa inferior es procedente contemplar conceptos, requisitos, impedimentos o trámites en la especie. En otras palabras, trátase de un asunto delicado, para cuya normativa se exige por la Constitución el mayor grado de certeza o seguridad posibles, circunstancia que justifica la reserva legal fuerte que hemos destacado. Queda excluida, por ende, la delegación de facultades legislativas en el tópico, así como el desempeño de la potestad reglamentaria por el Primer Mandatario. Lo explicado se halla corroborado con el texto y contexto minuciosos de la Carta Fundamental, rasgo exhaustivo, 
autoridad administrativa deberá verificar la concurrencia de las circunstancias cuando la medida desfavorable es pronunciada.

Por su parte, al encontrarnos frente a medidas que no tienen su sustento en incumplimiento de obligaciones, y por tanto carentes de una finalidad sancionatoria, no es necesario exigir que el particular haya inobservado los requisitos de ingreso mediando dolo o culpa, toda vez que "La culpabilidad exige que se pueda formular un reproche a la conducta del autor" ${ }^{50}$. Basta la verificación de que el particular haya ingresado sin cumplir los requisitos legales para que proceda la aplicación de la medida que corresponda ${ }^{51}$.

Respecto del principio de proporcionalidad, y de forma similar a lo que ocurre en materia sancionatoria ${ }^{52}$, este cumplirá un rol tanto respecto del ejercicio de las facultades del legislador como respecto de las facultades de la Administración. En lo relativo a la actividad del primero, "[...] el examen de proporcionalidad constituye un instrumento de control de constitucionalidad de medidas restrictivas de derechos fundamentales" 53 ; ya que es una exigencia que permite restringir o regular el ejercicio de derechos. En lo que corresponde a la actividad del segundo, en cambio, el foco se pone en la actividad de la Administración del Estado, quien deberá ponderar el fin perseguido por la medida con la eventual lesión de otros derechos.

Asimismo, y atendiendo al fundamento de la medida, no es posible afirmar la aplicación del principio de non bis in idem, salvo que se produzca la identidad del sujeto, objeto y fundamento entre el acto desfavorable y otras medidas que se adopten ${ }^{54}$, incluso penales.

En lo relativo al principio de irretroactividad in pejus, como bien señala Cordero, se trata de un principio aplicable " $[\ldots . .$.$] respecto de cualquier persona que se relaciona con$ los órganos administrativos frente a sus actos administrativos desfavorables, fundados en los principios de seguridad jurídica, confianza legítima y protección de los derechos adquiridos" 55 .

En efecto, de haber ingresado regularmente, el sujeto tiene el derecho de permanecer en territorio nacional en el plazo y condiciones fijadas por la visa respectiva.

Por último, y respecto de la prescriptibilidad, no es procedente aplicar la prescripción a efecto de impedir dar inicio al procedimiento administrativo del que resulte el acto desfavorable no sancionatorio, debido a que, al encontrar dicha medida su fundamento en la inobservancia de las condiciones de ingreso, y mientras no haya mediado algún acto de regularización o salida del país, dicha irregularidad tendrá el carácter de continuada.

casi de detalle, que permite comprender la trascendencia que tiene el asunto en el Estado de Derecho"; CEA, 2004, p. 232.

50 Cordero, 2014a, p. 422. Del mismo modo, véase Bermúdez, 2014, p. 343.

${ }^{51}$ En el caso de los refugiados, asilados y víctimas de trata y tráfico, deberá estarse a la regulación y derechos específicos de tales materias.

52 Véase Cordero, 2014 a, p. 423.

53 DíAz, 2011, p. 202.

${ }^{54}$ Por todos, véase a Gómez, 2017, pp. 114-115.

55 Cordero, 2014a, pp. 428-429. 
De este modo, aunque se estableciese un plazo de prescripción, el mismo sería impracticable. Lo anterior no debe ser confundido con el hecho de que, habiendo mediado un tiempo, la autoridad permita poner fin al estado de irregularidad, y, en consecuencia, a la posibilidad de dictar ciertos actos desfavorables, al permitir la regularización del extranjero. Cosa distinta ocurre respecto de la prescripción de la medida desfavorable no sancionatoria, caso en el que sí será posible aplicar la institución de la prescripción. En efecto, una vez que dicha medida sea dictada, no resulta procedente, a falta de una regla expresa de imprescriptibilidad, permitir que la medida dictada pueda ser aplicada sin límite temporal, hecho que, además, afecta la seguridad y certeza jurídica ${ }^{56}$. En cuanto al plazo, el mismo debe ser el de 5 años conforme con las normas del Código Civil ${ }^{57}$.

\section{Migrantes en territorio nacional}

Una vez que los extranjeros ingresen al territorio nacional, su relación con el Estado se dará en atención a la permanencia de aquellos en el territorio de este, debido a que el territorio estatal es el ámbito espacial de aplicación de las normas y preceptos emanados del Estado ${ }^{58}$. En el caso de los nacionales, en cambio, estos se encuentran vinculados permanentemente al Estado con quien tienen dicho vínculo, independiente del territorio en el que se encuentren, toda vez que su relación para con este es personal ${ }^{59}$.

Habiendo ingresado al territorio del Estado, los extranjeros quedarán sujetos a la normativa nacional ${ }^{60}$, siéndoles aplicables ciertos derechos y deberes ${ }^{61}$. Dentro de estos últimos se cuenta un conjunto de prohibiciones y obligaciones específicas establecidas por la ley y, cuya inobservancia, como ya se señaló, determinará una infracción a la normativa migratoria, independiente de la regularidad o irregularidad en la que se encuentre el

\footnotetext{
56 Véase a Cordero, 2020, p. 361.

57 VAllejo, 2016, p. 299.
}

58 Verdugo y García, 1991, p. 122. Lo que no obsta para que ciertos actos y hechos perpetrados en el extranjero puedan ser sometidos a la ley chilena, fenómeno conocido como extraterritorialidad de la ley. Véase Alessandri et al., 2005, p. 277 y siguientes.

59 Silva BASCUÑán define la nacionalidad como "[...] el vínculo que existe entre la persona y el Estado"; Silva, 1997, p. 182.

${ }^{60}$ El artículo $6^{\circ}$ de la Constitución exige la observancia de sus preceptos, así como de las leyes dictadas en su conformidad, a todas las personas, sin distinguir entre nacionales y extranjeros. Véase SiLVA, 1997, p. 135.

${ }^{61}$ Para JellineK, "La subjetividad [jurídica] se exterioriza mediante el reconocimiento que hace el Estado al individuo de su carácter de miembro en la comunidad popular; pero esto implica el reconocimiento del hombre como persona, esto es como individuo que posee una esfera de derecho público. Tal es el resultado de la evolución total de la cultura, según la cual, en el Estado moderno, todo hombre está sometido de algún modo al poder del Estado, es al propio tiempo, frente a él, persona. Por esto, aun cuando hoy la situación plena de miembro de un Estado dependa para el individuo de que pertenezca o no, permanentemente a este Estado, [por ser nacional de él,] el que, siquiera sea transitoriamente, se encuentre sometido al poder de un Estado extraño, no solo es considerado como subditus del mismo, sino también como cives temporarius, que si bien tienen deberes públicos tiene a su vez derechos de esta naturaleza"; Jellinek, 2000, p. 380. En el mismo sentido, ArletTAz expone la distinción entre el status personae, que corresponde a los derechos de la personalidad, y el status civitatis, que corresponde a los derechos de la ciudadanía; ArLETTAZ, 2014, p. 38. 
sujeto, salvo que la norma exija la irregularidad como requisito del tipo infraccional. En otras palabras, respecto de este segundo estatuto, lo que le importará al derecho es que el comportamiento del particular sea calificable como un incumplimiento de deberes, obligaciones y prohibiciones a las que está sujeto.

Por lo anterior, las consecuencias jurídicas que tengan lugar frente a este segundo tipo de comportamientos sí tendrán el carácter de sanciones administrativas, siendo a su respecto aplicables los diferentes principios de tal rama del derecho, es decir, los principios de: legalidad, tipicidad, irretroactividad, culpabilidad, proporcionalidad, personalidad, non bis in idem, existencia de un procedimiento previo, legal, justo y racional (dentro del que se encuentra comprendido el derecho a la defensa jurídica, la presunción de inocencia y el acceso a la justicia $)^{62}$.

En este punto, podría dudarse de la naturaleza jurídica de los actos desfavorables dictados respecto de aquellos extranjeros que, habiendo ingresado regularmente al país, permanecen en su territorio por más tiempo que el debido. Al respecto, creemos que la solución se encuentra en el valor que se le conceda a dicho plazo. En efecto, un extranjero que ingresa regularmente al país lo hace bajo una determinada visa, la que establecerá las condiciones específicas por las que el particular deberá ceñirse. De ello, y conforme con la tipología de visa que se trate, el particular tendrá un determinado tiempo para encontrarse en Chile, realizar ciertas actividades económicas, obtener determinados beneficios estatales, etc. La categoría migratoria en la que ingrese, además de ser indisponible para el extranjero, conlleva al establecimiento de varios deberes, obligaciones y prohibiciones, una de estas es la no permanencia en territorio nacional más allá del tiempo autorizado.

De esta manera, es posible afirmar que uno de los principales deberes que recaen sobre los extranjeros es cumplir con las condiciones de permanencia impuestas por sus visados, así como con las prohibiciones, deberes y obligaciones generales, evitando incurrir en irregularidad.

En este sentido, los artículos 107 y 119 de la PLM prescriben la aplicación de una multa respecto de aquellos extranjeros residentes o titulares de un permiso de residencia transitoria que permanezcan en el país por un plazo superior al tiempo permitido (la multa varía dependiendo si es que permanecen en el país por un plazo superior a 180 días desde la fecha de vencimiento del permiso respectivo).

El PLM establece la aplicación de la sanción de expulsión respecto de aquellos extranjeros que permanezcan en Chile no obstante haber vencido su permiso de permanencia transitoria (artículo $127 \mathrm{~N}^{\circ}$ 4), así como de aquellos residentes que permanezcan en suelo nacional, pese a haber vencido su respectivo permiso (artículo $128 \mathrm{~N}^{\circ} 4$ ). No obstante, y a efecto de prevenir una transgresión del principio de non bis in idem, conforme al artículo 122, inciso $2^{\circ}$ del PLM, en caso de disponerse la expulsión las multas que hubieran aplicado quedarán sin efecto.Por último, respecto de aquellas sanciones

\footnotetext{
${ }^{62}$ Cordero, 2014a, p. 409 y siguientes.
} 
que importen la afectación del ejercicio de la libertad circulatoria, el legislador verá su actividad limitada conforme con los límites expuestos previamente.

\section{Conclusiones}

1. Las sanciones administrativas son un especial tipo de acto desfavorable que puede adoptar la Administración del Estado. Para encontrarnos frente a una sanción administrativa en sentido estricto, es menester que exista un incumplimiento de deberes, obligaciones o prohibiciones a los que se encuentra sujeto el particular. Ello justifica que dichos actos desfavorables tengan una naturaleza castigadora o retributiva. En caso de encontrarnos frente a sanciones administrativas, la actividad del Estado estará sujeta a un conjunto de garantías sustantivas y procedimentales específicas, toda vez que dicha actividad es manifestación del ius puniendi estatal.

2. Si bien en el derecho internacional no existe un derecho a inmigrar, a la luz de nuestra Constitución dicho derecho sí se encuentra reconocido en favor de los extranjeros. Aun así, al estar sujeto su ejercicio a las reglas legales que correspondan, el particular deberá actuar en conformidad a dicha normativa. A lo dicho, es admisible destacar que el Estado no es absoluto en el ejercicio de sus atribuciones reguladoras, debiendo respetar los márgenes constitucionales que corresponda, así como aquellos provenientes de los tratados internacionales que correspondan.

3. Respecto del ejercicio de la libertad de circulación por parte de los extranjeros, es posible observar la existencia de un estatuto jurídico de ingreso y de un estatuto jurídico de permanencia.

4. En el estatuto jurídico de ingreso, el Estado regula aquellas condiciones bajo las cuales el extranjero podrá ingresar regularmente al territorio nacional, pero que, debido a la imposibilidad de hallarse dotado de vigencia extraterritorial, sus normas no imponen obligaciones, deberes o prohibiciones a las que el particular está sujeto, sino que establecen condiciones de acceso. De ello, las consecuencias que se deriven de la inobservancia de dichas normas no constituirán sanciones administrativas, debiendo reestablecerse al orden de cosas que corresponden. Es posible destacar que, si bien respecto de esta tipología de medidas no le son aplicables las garantías propias del derecho administrativo sancionador, la jurisprudencia, en una interpretación amplia de sanción, le ha hecho extensible sus principios procedimentales. Respecto de los principios sustantivos, es posible afirmar que varios de ellos son aplicables, incluso con mayor rigurosidad, mientras que otros no.

5. Finalmente, en lo que corresponde al segundo estatuto, el particular una vez ingrese a territorio nacional, independiente de su regularidad o irregularidad, se encontrará sujeto a deberes, obligaciones y prohibiciones, cuyo incumplimiento conlleva a la aplicación de sanciones administrativas, esto es, actos administrativos desfavorables de naturaleza represiva o de castigo. Misma situación existirá 
respecto de aquellos extranjeros que, habiendo ingresado regularmente, han devenido en irregulares, habida cuenta de su permanencia en territorio nacional por un plazo superior al permitido en su respectiva visa.

\section{BIBLIOGRAFÍA}

\section{Doctrina}

Aldunate Lizana, Eduardo, 2008: Derechos Fundamentales, Santiago de Chile, Legal Publishing. Alessandri, Arturo; Somarriva, Manuel y Vodanovic, Antonio, 2005: Tratado de Derecho Civil ( $5^{\circ}$ edición), Tomo I, Santiago de Chile, Editorial Jurídica de Chile.

Aninat, Isabel y Sierra Lucas, 2019: "Regulación inmigratoria: propuestas para una mejor reforma”, en Isabel Aninat y Rodrigo Vergara (editores), Inmigración en Chile. Una mirada multidimensional, Santiago de Chile, Fondo de Cultura Económica, pp. 31-63.

ArlettAz, Fernando, 2014: Extranjeros y migrantes: cuatro cuestiones de derecho internacional y filosofía jurídica, Madrid, Fundación Aequitas - Fundación Aranzadi Lex Nova.

Bassa Mercado, Jaime y Torres Villarrubia, Fernanda, 2015: "Desafíos para el ordenamiento jurídico chileno ante el crecimiento de los flujos migratorios”, Estudios Constitucionales, año 13, $\mathrm{N}^{\mathrm{o}} 2$, pp. 103-124.

Bassa Mercado, Jaime y Torres Villarrubia, Fernanda, 2020: "Derechos de los migrantes", en Pablo Contreras y Constanza Salgado, Curso de Derechos Fundamentales, Valencia, Tirant lo Blanch, pp. 1021-1052.

Bermúdez Soto, Jorge, 1998: "Elementos para definir las sanciones administrativas", Revista Chilena de Derecho, número especial, pp. 323-334.

Bermúdez Soto, Jorge, 2014: Derecho administrativo general (3ºdición), Santiago de Chile, Legal Publishing - Thomson Reuters.

Cea Egaña, José Luis, 2008: Derecho constitucional chileno (2 edición), Tomo II, Santiago de Chile, Ediciones UC.

Cordero Quinzacara, Eduardo, 2013: "Concepto y naturaleza de las sanciones administrativas en la doctrina y jurisprudencia chilena”, Revista de Derecho (Coquimbo), año 20, No 1, pp. 79-113.

Cordero Quinzacara, Eduardo, 2014a: "Los principios que rigen la potestad sancionadora de la Administración en el Derecho Chileno", Revista de Derecho (Valparaíso), volumen 42, pp. 399-439.

Cordero Quinzacara, Eduardo, 2014b: "Los principios y reglas comunes al procedimiento administrativo sancionador”, en Jaime Arancibia Mattar y Pablo Alarcón Jaña (coordinadores), Sanciones Administrativas, Santiago de Chile, Legal Publishing - Thompson Reuters, pp. 189-215.

Cordero Quinzacara, Eduardo, 2020: "El plazo de prescripción de las infracciones y sanciones administrativas", Revista Chilena de Derecho, volumen 47, No 2, pp. 359-384.

Cordero Vega, Luis, 2020: "El derecho administrativo sancionador y los sectores de referencia en el sistema institucional chileno", Ius et Praxis, año 26, $\mathrm{N}^{\circ}$ 1, pp. 240-265.Cox, Adam B., 2008: "Inmigration law's organizing principles”, University of Pensilvania Law Review, volumen $157, \mathrm{~N}^{\circ} 2$, pp. 341-393.

Dellacasa Aldunate, Francisco José y Hurtado Fernández, José María, 2015: Derecho migratorio chileno, Santiago de Chile, Editorial Jurídica de Chile. 
DíAz GARCíA, L. Iván, 2011: "La aplicación del principio de proporcionalidad en orden a juzgar sobre la licitud o ilicitud de una restricción a derechos fundamentales", Revista de Derecho (Valparaíso), No 36, pp. 167-206.

DíAz Tolosa, Regina Ingrid, 2016: "Ingreso y permanencia de las personas migrantes en Chile: compatibilidad de la normativa chilena con los estándares internacionales”, Estudios Constitucionales, año 14, Nº 1, pp. 179-220.

Domínguez Valverde, Cecilia Andrea, 2016: "Derechos chileno migratorio a la luz del derecho migratorio internacional: ¡ceden los derechos humanos mínimos de los extranjeros ante las prerrogativas soberanas de control migratorio", Revista Chilena de Derecho, volumen 43, $\mathrm{N}^{\circ}$ 1, pp. 189-217.

Enteiche Rosales, Enrique, 2014: “¿Qué es una “sanción administrativa” en Chile?”, en Jaime Arancibia Mattar y Pablo Alarcón Jaña (coordinadores), Sanciones Administrativas, Santiago de Chile, Legal Publishing - Thompson Reuters, pp. 3-15.

Fuentes, Adolfo y Hernando, Andrés, 2019: "Caracterización estadística de la inmigración en Chile”, en Isabel Aninat y Rodrigo Vergara (editores), Inmigración en Chile. Una mirada multidimensional, Santiago de Chile, Fondo de Cultura Económica, pp. 379-407.

García Maynez, Eduardo, 1965: Introducción al estudio del derecho (13º edición), Ciudad de México, Editorial Porrua S.A.

Gómez GonzÁLEz, Rosa Fernanda, 2017: "El non bis in ídem en el derecho administrativo sancionador. Revisión de sus alcances en la jurisprudencia administrativa”, Revista de Derecho (Valparaíso), volumen 49, pp. 101-138.

Gómez GonzÁlez, Rosa Fernanda, 2020: “Discrecionalidad y potestades sancionadoras de la Administración”, Ius et Praxis, año 26, No 2, pp. 193-218.

InSTITUTO NaCiONAL DE ESTAdístiCAS Y DEPARTAMENTO DE EXTRANJERÍA Y Migración, 2020: Estimación de personas extranjeras residentes habituales en Chile al 32 de diciembre 2020. Disponible en https://www. ine.cl/docs/default-source/demografia-y-migracion/publicaciones-y-anuarios/migraci\%C3\% B3ninternacional/estimaci\%C3\% B 3n-poblaci\%C3\%B3n-extranjera-en-chile-2018/ estimaci\%C3\%B3n-poblaci\%C3\%B3n-extranjera-en-chile-2019-metodolog\%C3\% ADa. pdf?sfvrsn=5b145256_6. [Fecha de consulta: 12.12.2020].

Huergo Lora, Alejandro, 2007: Las sanciones administrativas, Madrid, Iustel.

Jellinek, George, 2000: Teoría general del Estado, Ciudad de México, Fondo de Cultura Económica.

Камто, Maurice, 2006: Segundo informe sobre expulsión de los extranjeros presentado por el Relator Especial, Ginebra: Naciones Unidas.

Lages De Oliveira, Rita, 2019: "Migración internacional y derecho: una reflexión en clave de derechos humanos”, Revista Anales, No 16, pp. 27-45.

Letelier Wartenberg, Raúl, 2018: "Principios y funciones en las sanciones administrativas", en Alberto Montaña Plata y Jorge Iván Rincón Córdoba (editores), El poder sancionador de la administración pública: discusión, expansión y construcción, Bogotá, Universidad Externado de Colombia, pp. 920-950.

Molina Conzué, Diego Andrés, 2018: "Discrecionalidad administrativa e igualdad ante la ley en materia migratoria”, en Actas de la I Bienal Latinoamericana de Derechos Humanos. Disponible en https://bienaldidh.org/wp-content/uploads/2019/04/Acta-Molina.pdf. [Fecha de consulta: 19.07.2019].

Molina Conzué, Diego Andrés, 2019: "Principios de derecho migratorio chileno desde una óptica constitucional”; en John Charney (editor), Derecho y Migración, Valparaíso, EUV, pp. 235-251.

Nieto, Alejandro, 2016: Derecho Administrativo sancionador (reimp., $5^{\circ}$ edición), Madrid: Tecnos. 
Osorio VARgas, Cristóbal Salvador, 2017: Manual de procedimiento administrativo sancionador $\left(2^{\circ}\right.$ edición), Santiago de Chile, Thomson Reuters.

Pérez Serrano, Nicolás, 1994: Tratado de Derecho Político, Madrid, Civitas.

Silva Bascuñán, Alejandro, 1997: Tratado de Derecho Constitucional, Tomo IV, Santiago de Chile, Editorial Jurídica de Chile.

STANG, María Fernanda, 2016: "De la Doctrina de la Seguridad Nacional a la gobernabilidad migratoria: la idea de seguridad en la normativa migratoria chilena, 1975-2014”, Revista Latinoamericana, volumen 15, $\mathrm{N}^{\circ} 44$, pp. 83-107.

Uprimny Yepes, Rodrigo y Sánchez Duque, Luz María, 2019: “Artículo 22. Derecho de Circulación y de Residencia”, en Christian Steiner y Marie-Christine Fuchs (editores), Convención Americana sobre Derechos Humanos. Comentario ( $2^{\circ}$ edición), Bogotá Konrad Adenauer Stiftung, pp. 645-670.

VAllejo Garretón, Rodrigo, 2016: “Acerca del régimen supletorio de prescripción aplicable a las infracciones y sanciones administrativas", Revista de Derecho (Valparaíso), volumen 47, pp. 281-301.

Verdugo Marinkovic, Mario y García Barzelatto, Ana María, 1991: Manual de Derecho Político (reimp., $2^{\circ}$ edición), Santiago de Chile, Editorial Jurídica de Chile.

\section{Normativa}

Decreto Ley 1.094, del Ministerio del Interior, Establece normas sobre extranjeros en Chile. Publicado en Chile con fecha 14 de julio de 1975.

Proyecto de Ley de Migración y Extranjería, Boletín No 8.970-06.

\section{Jurisprudencia}

CoRTe Interamericana de Derechos Humanos, sentencia de 23 de noviembre de 2010, caso Vélez Loor vs Panamá. Excepciones preliminares, fondo, reparaciones y costas. Serie C No 218.

Corte Interamericana de Derechos Humanos, sentencia de 28 de agosto de 2014, caso de Personas Dominicanas y Haitianas Expulsadas. Excepciones preliminares, fondo, reparaciones y costas. Serie C No 282.

Tribunal Constitucional, sentencia de 28 de agosto de 1996, rol 244-1996.

Tribunal Constitucional, sentencia de 4 de julio de 2013, rol 2.273-2012. 
